\title{
Reign Periods of the Ming and Qing Dynasties
}

$\begin{array}{lcll}\text { MING (I368-I644) } & \text { QING (I644-I9II) } \\ \text { Hongwu } & \text { I368-I398 } & \text { Shunzhi } & \text { I644-I66I } \\ \text { Jianwen } & \text { I399-I402 } & \text { Kangxi } & \text { I662-I722 } \\ \text { Yongle } & \text { I403-I424 } & \text { Yongzheng } & \text { I723-I735 } \\ \text { Hongxi } & \text { I424-I425 } & \text { Qianlong } & \text { I736-I795 } \\ \text { Xuande } & \text { I426-I435 } & \text { Jiaqing } & \text { I796-I820 } \\ \text { Zhengtong } & \text { I436-I449 } & \text { Daoguang } & \text { I 82I-I850 } \\ \text { Jingtai } & \text { I450-I456 } & \text { Xianfeng } & \text { I 85I-I86I } \\ \text { Tianshun } & \text { I457-I464 } & \text { Tongzhi } & \text { I 862-I874 } \\ \text { Chenghua } & \text { I465-I487 } & \text { Guangxu } & \text { I 875-I907 } \\ \text { Hongzhi } & \text { I488-I505 } & \text { Xuantong } & \text { I908-I9I I } \\ \text { Zhengde } & \text { I 506-I52I } & & \\ \text { Jiajing } & \text { I522-I566 } & & \\ \text { Longqing } & \text { I567-I572 } & & \\ \text { Wanli } & \text { I573-I620 } & & \\ \text { Taichang } & \text { I620-I620 } & & \\ \text { Tianqi } & \text { I62I-I627 } & & \\ \text { Chongzhen } & \text { I628-I644 } & & \end{array}$

